\title{
Studi Eksperimen Pengaruh Sudut Pitch terhadap Karakteristik Performa pada Turbin Angin Counter- Rotating
}

\author{
F.A. Azhar* dan M.A. Bramantya \\ Departemen Teknik Mesin dan Industri, Fakultas Teknik, Universitas Gadjah Mada. \\ Jl. Grafika No.2, Kompleks UGM, Yogyakarta 55281, Indonesia, \\ Telp. (0274) 521673 \\ e-mail: averoazhar@gmail.com
}

\begin{abstract}
Abstrak
Pemanfaatan energi angin menjadi daya berguna menuntut peningkatan efisiensi turbin angin. Cara lain untuk meningkatkan efisiensi dengan menggunakan turbin angin counter-rotating. Pada penelitian ini dilakukan pengamatan performa dari turbin angin full Scale model counter-rotating (CRWT) dengan sebuah generator dan roda gigi. Pengujian dilakukan pada kondisi lingkungan sebenarnya dan kecepatan angin yang fluktuatif. Rotor turbin depan dan belakang menggunakan 3 buah bilah dengan rasio diameter $\left(\mathrm{D}_{1} / \mathrm{D}_{2}\right)=0,5$. Desain aerodinamika bilah turbin counterrotating dibuat berdasarkan perhitungan menggunakan teori Blade Element Momentum (BEM). Sudut pitch rotor turbin diatur sebesar $0^{\circ}, 10^{\circ}$ dan $20^{\circ}$ dan diamati daya elektrik keluaran dari generator untuk mengetahui perbedaan performa dari masing-masing variasi. Koefisien daya maksimum yang dihasilkan oleh rotor pada kecepatan angin $4 \mathrm{~m} / \mathrm{s}$ sampai $7 \mathrm{~m} / \mathrm{s}$ dengan sudut pitch $0^{\circ}$ sebesar $4,5 \times 10^{-3}$. Sedangkan turbin angin dengan sudut pitch rotor $10^{\circ}$ dan $20^{\circ}$ koefisien daya tertinggi masing-masing tercapai sebesar $3,6 \times 10^{-3}$ dan $3,3 \times 10^{-3}$. Hasil pengujian menunjukkan semakin besar sudut pitch koefisien daya yang dihasilkan pada kecepatan angin rendah semakin besar, akan tetapi semakin tinggi kecepatan angin rotor dengan sudut pitch kecil menghasilkan koefisien daya yang lebih besar.
\end{abstract}

Kata kunci : turbin angin counter-rotating, sudut pitch, performa, pengujian lingkungan.

\begin{abstract}
In order to improve the efficiency of wind turbine, counter-rotating wind turbine was proposed. In this study the performance of a full-scale counter-rotating model of wind turbine was observed with a generator and gears. The test carried out in actual environmental conditions and fluctuating wind speeds. Front and rear turbine rotors use 3 blades with a diameter ratio (D1 / D2) $=0.5$. The aerodynamic design of the counter-rotating turbine blades calculated based on the Blade Element Momentum (BEM) theory. The pitch angle of the turbine rotors were set at $0^{\circ}, 10^{\circ}$ and $20^{\circ}$ and the electric power output of the generator was observed to determine the difference in performance of each variation. The maximum power coefficient produced by the rotor at wind speed $4 \mathrm{~m} / \mathrm{s}-7 \mathrm{~m} / \mathrm{s}$ with pitch angle of $0^{\circ}$ is $4,5 \times 10^{-3}$. Whereas wind turbines with rotor pitch angles of $10^{\circ}$ and $20^{\circ}$ the highest power coefficients were achieved at $3,6 \times 10^{-3}$ and $3,3 \times 10^{-3}$. The test results shows, increased pitch angle
\end{abstract}


produced more power coefficient at low wind speeds, but in the high wind speed, rotor with a small pitch angle performed better.

Keywords : counter-rotating wind turbine, pitch angle, performance, environtmental test.

\section{PENDAHULUAN}

Perkembangan turbin angin saat ini dilatar belakangi berkurangnya potensi energi fosil terutama minyak dan gas bumi, sehingga mendorong Energi Baru dan Terbarukan (EBT) sebagai prioritas utama untuk menjaga ketahanan dan kemandirian energi. Di Indonesia sendiri potensi energi baru terbarukan (EBT) belum dimanfaatkan secara maksimal termasuk di dalamnya sumber daya angin.

Berdasarkan hasil survei potensi sumber daya angin dari beberapa daerah yang dihimpun, diperoleh kecepatan angin di Indonesia tergolong pada kecepatan angin rendah yaitu dalam rentang $3-5,5 \mathrm{~m} / \mathrm{s}$. Sehingga penting untuk dilakukan pengembangan turbin angin yang dapat memanfaatkan energi angin secara maksimal dengan kondisi kecepatan angin yang rendah namun menghasilkan daya yang tinggi.

Sebagian besar turbin angin yang digunakan saat ini memiliki desain turbin dengan rotor tunggal yang memiliki tiga bilah rotor yang dipasang pada bub di depan rumah generator seperti yang ditunjukkan pada Gambar 1a. Berdasarkan teori batas Betz, turbin angin sumbu horizontal rotor tunggal (HAWT) dapat menangkap energi angin maksimum 59,3\% yang melewati luasan area turbin dengan asumsi aliran satu dimensi, stabil dan tidak dapat dimampatkan. Di sisi lain, untuk mencapai efisiensi aerodinamika 59,3\% sesuai teori batas Betz tidak dapat direalisasikan oleh HAWT rotor tunggal. Hukum fisika dan kendala lain membatasi efisiensi tidak lebih besar dari sekitar 53\%.

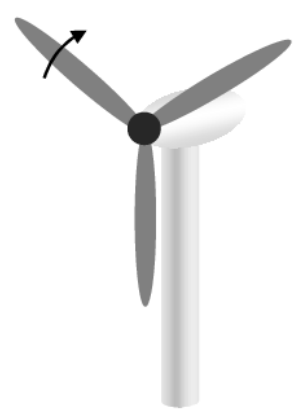

a)

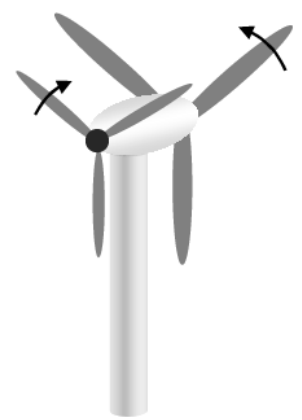

b)

Gambar 1. a) Turbin angin rotor tunggal, b) Turbin angin counter-rotating

Cara lain untuk meningkatkan efisiensi turbin angin adalah dengan menggunakan metode turbin angin rotor ganda. Metode tersebut menggunakan 2 rotor dalam satu poros sehingga jika dibandingkan dengan turbin dengan rotor tunggal, luas penampang rotor yang sama akan menghasilkan daya lebih karena angin datang ditangkap oleh dua buah rotor. Dengan mempertimbangkan fenomena wake dan pembangkitan aliran vortex setelah udara melewati rotor depan, konfigurasi putaran pada turbin angin rotor ganda diatur berputar saling berlawanan arah yang saat ini dikenal dengan turbin angin counter-rotating seperti pada Gambar 1b. Model turbin angin counter-rotating berpotensi secara efektif dapat menghasilkan koefisien daya lebih besar dibandingkan turbin rotor tunggal disebabkan aliran wake di belakang rotor 
depan cenderung berputar berlawanan dengan arah rotasi rotor depan, sehingga rotor belakang harus berputar searah dengan putaran wake agar dapat menyerap energi angin lebih efektif. Hal tersebut dibuktikan oleh Wei dkk. dengan melakukan pengamatan pada 2 model turbin disusun segaris yang berputar co-rotating dan counter-rotating membuktikan daya yang dihasilkan kedua turbin dengan konfigurasi counter-rotating lebih besar dari pada co-rotating. Newman merumuskan model matematika dan melakukan simulasi numerik satu dimensi dari turbin rotor ganda dan rotor tak hingga, nilai batas koefisien daya teoritis diprediksi mampu mencapai 64\% untuk turbin rotor ganda dan 66,7\% untuk rotor tak hingga melebihi dari batas Betz untuk rotor tunggal dengan batas maksimum 59\%.

Kajian numerik turbin angin counter-rotating telah dilakukan oleh Buana dkk. dengan variasi rasio diameter rotor depan dan belakang sebesar 0,5 hingga 2,0. Selain itu, Lee, dkk. melakukan analisa karakteristik aerodinamika dengan membandingkan jumlah bilah pada turbin angin rotor tunggal dan rotor ganda. Dari kedua penelitian tersebut menunjukkan peningkatan pada koefisien daya yang dihasilkan oleh turbin angin counter-rotating.

Melalui kajian eksperimental pada cerobong angin, Mitulet dkk. memvariasikan model bilah rotor dengan rasio diameter rotor 1:1 pada jarak rotor $1 \mathrm{~m}$. Sementara Zhiqiang dkk. melakukan pengamatan terhadap berbagai rasio diameter dan sudut pitch turbin angin counter-rotating. Kedua penelitian tersebut membuktikan terdapat peningkatan daya pada turbin angin counter-rotating apabila dibandingkan dengan turbin angin rotor tunggal.

Dari beberapa studi literatur di atas pengujian turbin angin counter-rotating masih sebatas pengujian simulasi dan eksperimental pada cerobong angin. Sehingga dirasa perlu untuk dilakukan pengamatan terhadap hasil performa yang dihasilkan pada kondisi lingkungan langsung untuk membuktikan teori yang berkembang pada turbin angin counter-rotating. Pada penelitian ini akan dilakukan pengamatan performa dari turbin angin full Scale model counterrotating dengan sebuah generator dan roda gigi. Desain rotor turbin disesuaikan dengan kondisi kecepatan angin rata-rata pada lokasi penelitian. Pengaruh perubahan sudut pitch pada rotor turbin lebih difokuskan pada pengujian performa turbin angin counter-rotating.

Gambar 2 menunjukkan informasi tentang kecepatan dan distribusi gaya yang tercipta pada elemen bilah rotor. Sudut pitch adalah sudut yang terbentuk antara chordline dan bidang rotasi rotor pada kondisi desain. Pada penelitian ini sudut pitch akan divariasikan sebesar $0^{\circ}, 10^{\circ}$, dan $20^{\circ}$. 


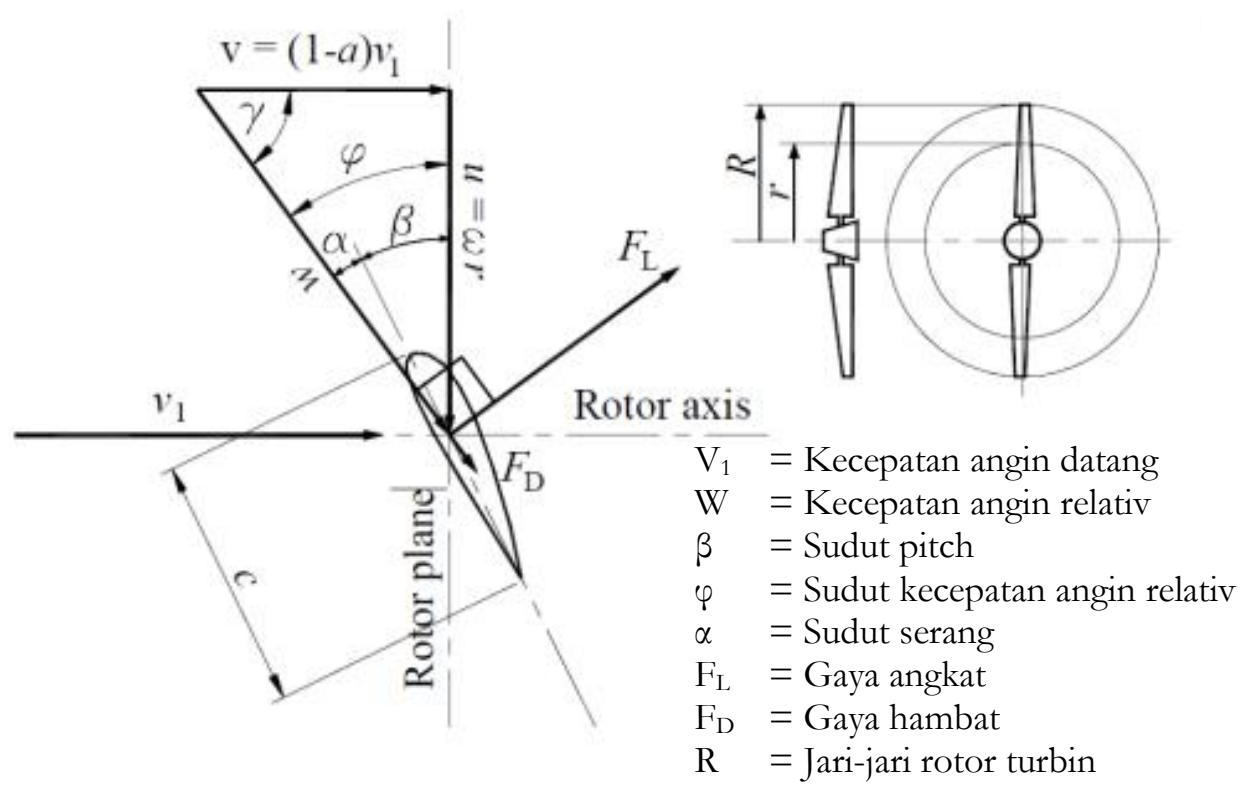

Gambar 2. Diagram vektor kecepatan dan gaya yang bekerja pada bilah turbin

\section{METODE PENELITIAN}

\subsection{Desain Bilah Turbin}

Desain aerodinamika bilah turbin counter-rotating dibuat berdasarkan perhitungan menggunakan teori Blade Element Momentum (BEM). Profil NACA 4415 dipilih sebagai bentuk dasar bilah dari pangkal bilah hingga ujung bilah karena memiliki perbandingan koefisien gaya angkat dan koefisien gaya hambat $\left(\mathrm{C}_{\mathrm{L}} / \mathrm{C}_{\mathrm{D}}\right)$ yang tinggi dibandingkan dengan beberapa tipe profil airfoil lain (S822, S833, NACA 4412) pada kecepatan angin rendah [12]. Rotor turbin depan dan belakang menggunakan 3 buah bilah dengan rasio diameter $\left(D_{1} / D_{2}\right)=0,5$. Kecepatan angin perancangan ditentukan sebesar $5,5 \mathrm{~m} / \mathrm{s}$ sesuai dengan kondisi angin di wilayah pengujian dan RPM yang ingin dicapai sebesar 500 RPM berdasarkan putaran kerja optimal dari generator. Sehingga dengan menggunakan teori BEM dan pengembangan yang dilakukan oleh Schmitz terbentuk distribusi panjang chord (c) dan sudut puntir pada bilah $(\beta)$ untuk rotor depan maupun belakang sesuai dengan Gambar 3. Selanjutnya pada Tabel 1 memperlihatkan spesifikasi rotor turbin angin yang digunakan. 


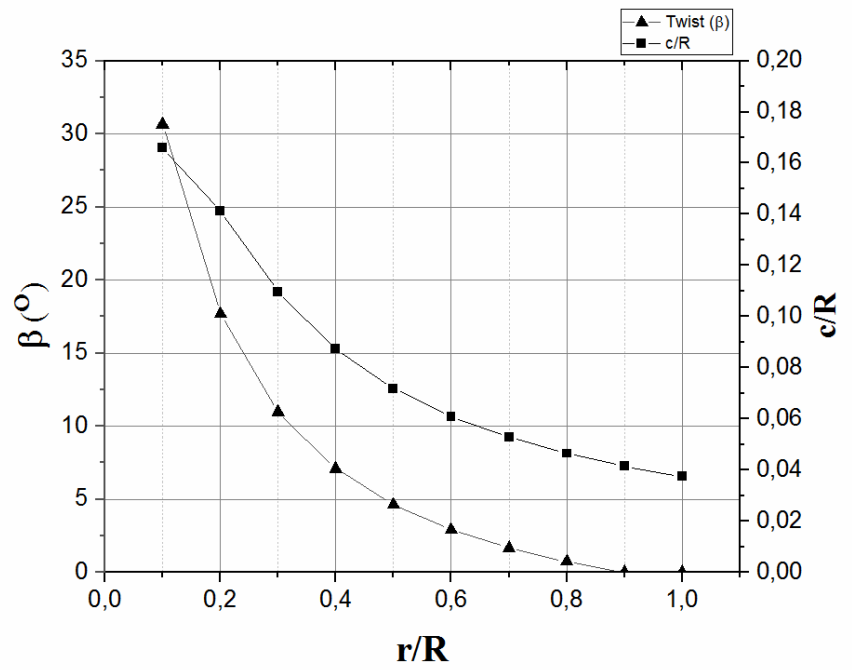

Gambar 3. Distribusi chord dan sudut twist

Tabel 1. Spesifikasi Rotor Turbin

\begin{tabular}{lll}
\hline Spesifikasi & Rotor Depan & Rotor Belakang \\
\hline Diameter & $75 \mathrm{~cm}$ & $150 \mathrm{~cm}$ \\
Jumlah Bilah & 3 & 3 \\
Airfoil & NACA 4415 & NACA 4415 \\
Sudut Serang desain & $6^{\circ}$ & $6^{\circ}$ \\
RPM desain & 500 & 500 \\
Arah Putaran & Counter-clockwise & Clockwise \\
\hline
\end{tabular}

\subsection{Prosedur Pengambilan Data}

Penelitian Turbin angin counter-rotating ini dilakukan secara eksperimental, dimana turbin angin dipasang dipinggir pantai selatan Yogyakarta dengan kecepatan angin rata-rata 5,5 m/s. Pengumpulan data dilakukan berdasarkan kecepatan angin yang tercapai saat pengujian. Alat ukur kecepatan angin menggunakan anemometer mangkok yang ditempatkan di depan rotor dengan jarak $1 \mathrm{~m}$. Variasi sudut pitch rotor turbin sebesar $0^{\circ}, 10^{\circ}$ dan $20^{\circ}$ dengan sudut ujung bilah sebagai acuan pengaturan sudut dan dilakukan pengamatan terhadap daya elektrik yang dihasilkan dari generator untuk mengetahui perbedaan performanya dari masing-masing variasi. Selanjutnya kontrol variabel pada penelitian ini adalah jumlah bilah rotor 3 buah pada rotor depan dan belakang, jarak aksial antara kedua buah rotor $0,4 \mathrm{~m}$ dan rasio diameter rotor 0,5. Bilah rotor terbuat dari material komposit fiberglass. Generator turbin menggunakan generator DC merek RAE Corporation dengan tegangan maksimum yang dihasilkan sebesar 20 VDC. Generator dihubungkan dengan 2 buah lampu AC yang masing-masing lampu memiliki daya maksimum 25 Watt dan disusun secara paralel. Perekaman data kecepatan angin, putaran rotor, tegangan dan arus dilakukan menggunakan data logger setiap 4 detik untuk melihat karakteristik performa rotor. Selanjutnya dari data yang diperoleh diambil daya maksimum yang mampu dihasilkan oleh generator pada tiap kecepatan angin. 


\subsubsection{Pengukuran Performa Turbin Angin Counter-Rotating}

Parameter performa dari turbin angin bergantung pada daya keluaran dari turbin dan koefisien daya yang akan dievaluasi menggunakan persamaan (1) dan (2)

$$
\begin{aligned}
& P_{T}=V I \\
& C_{P}=\frac{P_{T}}{P_{W}}=\frac{V I}{\frac{1}{2} \rho A V_{\infty}^{3} \eta_{\text {gen }} \eta_{\text {gearbox }}}
\end{aligned}
$$

Daya dari turbin dihitung berdasarkan perkalian tegangan $(\mathrm{V})$ dan arus (I) yang dihasilkan generator. adapun koefisien daya $\left(C_{p}\right)$ merupakan bilangan tak berdimensi yang merepresentasikan efisiensi turbin. Koefisien daya didapat dari perbandingan antara daya rotor yang dihasilkan dan daya yang terdapat pada hembusan angin seperti yang dirumuskan pada persamaan (2) dimana, @ merupakan densitas udara $\left(\mathrm{kg} / \mathrm{m}^{3}\right)$ yang ditentukan sebesar 1,224 $\mathrm{kg} / \mathrm{m}^{3}, \mathrm{~A}$ adalah luas area rotor yang dalam penelitian ini diambil luas area rotor terbesar, dan $V_{\infty}$ adalah kecepatan angin.

\section{HASIL DAN PEMBAHASAN}

Pada Gambar 4 menunjukkan daya keluaran rata-rata yang dihasilkan generator pada rentang kecepatan angin $4 \mathrm{~m} / \mathrm{s}$ hingga $7 \mathrm{~m} / \mathrm{s}$. Daya yang dihasilkan oleh rotor dengan berbagai variasi sudut pitch menunjukkan tren yang sama dimana peningkatan daya berbanding lurus terhadap peningkatan kecepatan angin. Daya terbesar yang dihasilkan turbin dengan sudut pitch $0^{\circ}$ sebesar 5,84 watt. Selanjutnya untuk rotor dengan sudut pitch $10^{\circ}$ dan $20^{\circ}$ rata-rata daya maksimum yang dihasilkan sebesar 4,71 dan 4,25 watt. Tren yang sama juga ditunjukkan pada penelitian sebelumnya yang dilakukan oleh Sutrisno dkk. bahwa pembangkitan daya akan meningkat seiring dengan meningkatnya kecepatan angin. Daya keluaran yang semakin meningkat tersebut dikarenakan putaran rotor yang semakin tinggi akibat penyerapan daya angin oleh bilah rotor. Daya merupakan hasil perkalian antara tegangan dan arus yang dihasilkan generator. Peningkatan putaran generator yang dipengaruhi putaran rotor turbin menimbulkan gaya gerak listrik untuk menghasilkan tegangan dan arus.

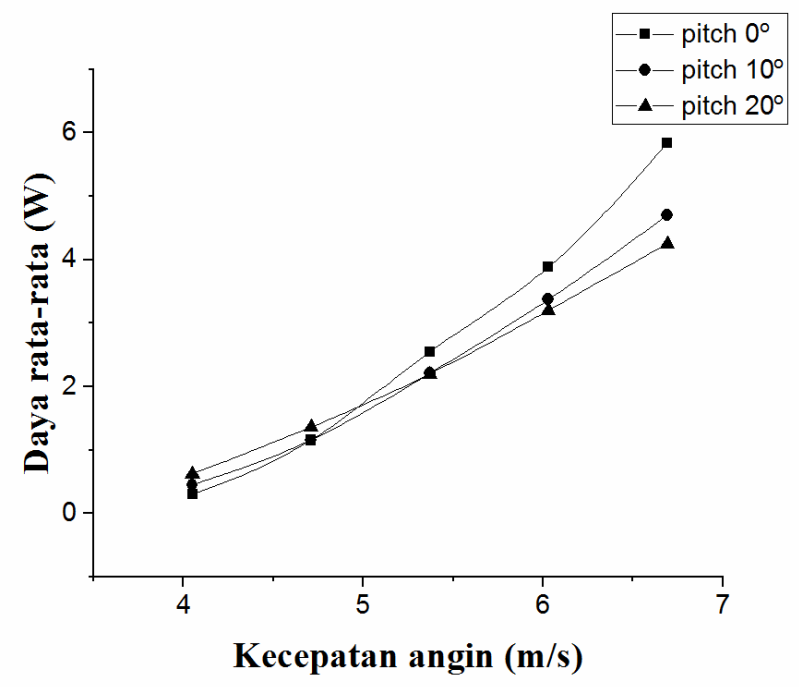

Gambar 4. Daya generator terhadap kecepatan angin 
Koefisien daya pada turbin angin sebagai indikator kemampuan turbin angin dalam menyerap energi yang terdapat pada angin ditunjukkan pada Gambar 5. Dari gambar tersebut menunjukkan karakteristik performa turbin angin counter-rotating terhadap perubahan sudut pitch dari hasil perhitungan menggunakan persamaan 2. Pada pengujian ini koefisien daya tertinggi dicapai oleh turbin angin dengan sudut pitch $0^{\circ}$ dengan nilai $11,6 \times 10^{-3}$. Sedangkan turbin angin dengan sudut pitch rotor $10^{\circ}$ koefisien daya tertinggi tercapai sebesar $9,4 \times 10^{-3}$ dan untuk rotor dengan sudut pitch $20^{\circ}$ koefisien daya tertinggi tercapai sebesar 8,7 $\times 10^{-3}$.

Dari Gambar 5 menunjukkan pengaruh perubahan sudut pitch terhadap performa dari turbin angin counter-rotating, dimana semakin besar sudut pitch koefisien daya yang dihasilkan pada kecepatan angin kurang dari $5 \mathrm{~m} / \mathrm{s}$ akan semakin besar, akan tetapi semakin tinggi kecepatan angin, rotor turbin yang memiliki sudut pitch $0^{\circ}$ mampu menghasilkan koefisien daya lebih besar. Fenomena tersebut dipengaruhi oleh sudut serang yang terbentuk dari masing-masing variasi sudut pitch rotor. Perubahan sudut pitch akan mempengaruhi sudut serang yang terbentuk pada permukaan bilah rotor. Hal tersebut mempengaruhi terbentuknya separasi pada permukaan bilah rotor yang mampu memperburuk kinerja dari rotor. Asumsi tersebut perlu dibuktikan dengan melakukan pengamatan terhadap medan aliran di area bilah dengan menggunakan CFD pada penelitian lebih lanjut. Pada kecepatan angin kurang dari $5 \mathrm{~m} / \mathrm{s}$ rotor dengan sudut pitch $20^{\circ}$ menghasilkan sudut serang optimum, sehingga rasio gaya angkat dan gaya hambat $\left(\mathrm{C}_{\mathrm{L}} / \mathrm{C}_{\mathrm{D}}\right)$ berada pada kondisi maksimum untuk desain bilah dipakai dalam penelitian ini. Sebaliknya untuk rotor dengan sudut pitch $0^{\circ}$, sudut serang dan $C_{L} / C_{D}$ optimum dicapai ketika kecepatan angin lebih dari $5,5 \mathrm{~m} / \mathrm{s}$.

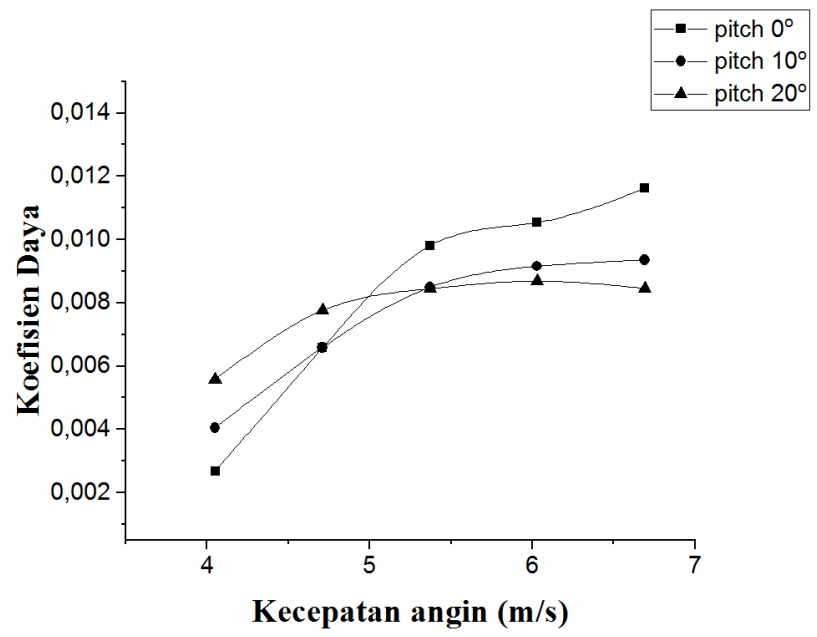

Gambar 5. Koefisien daya terhadap kecepatan angin

\section{KESIMPULAN}

Dari hasil pengujian eksperimen turbin angin counter-rotating yang dilakukan pada kondisi lingkungan aktual telah berhasil dilakukan. Pengujian turbin angin counter-rotating berhasil dilakukan pada rentang kecepatan angin $4 \mathrm{~m} / \mathrm{s}$ hingga $7 \mathrm{~m} / \mathrm{s}$. Dapat disimpulkan bahwa perubahan sudut pitch pada rotor mempengaruhi performa turbin angin. Pada rentang kecepatan angin 4-5 m/s semakin besar sudut pitch koefisien daya yang dihasilkan semakin besar. Akan tetapi dengan meningkatnya kecepatan angin, rotor dengan sudut pitch kecil menghasilkan 
koefisien daya lebih besar. Koefisien daya maksimum yang dihasilkan oleh rotor dengan sudut pitch $0^{\circ}$ sebesar $11,6 \times 10^{-3}$. Sedangkan turbin angin dengan sudut pitch rotor $10^{\circ}$ dan $20^{\circ}$ koefisien daya tertinggi masing-masing tercapai sebesar $9,4 \times 10^{-3}$ dan $8,7 \times 10^{-3}$.

Berdasarkan hasil pengujian diketahui bahwa rotor dengan sudut pitch tinggi memberikan manfaat pada cut-in speed yang rendah sehingga menjadikan turbin mudah berputar saat kecepatan angin rendah. Hal tersebut tidak terjadi pada rotor dengan sudut pitch rendah, akan tetapi untuk rotor dengan sudut pitch rendah mampu menghasilkan putaran rotor paling tinggi. Pengaruh perubahan sudut pitch terhadap cut-in speed tersebut lebih lanjut perlu dilakukan dengan menggunakan cerobong angin.

\section{DAFTAR PUSTAKA}

A. Rosenberg, S. Selvaraj, and A. Sharma, "A novel dual-rotor turbine for increased wind energy capture,” J. Phys. Conf. Ser., vol. 524, no. 1, 2014.

B. Newman, "Multiple Actuator-Disc Theory for Wind Turbines," vol. 24, pp. 215-225, 1986.

Hermawan, M. A. Bramantya, N. K. Majid, and A. Febrianto, "Experimental study effect of flange addition on mechanical power of diffuser augmented counter rotating wind turbine," AIP Conf. Proc., vol. 2001, pp. 3-10, 2018.

L. A. Mitulet, G. Oprina, R. A. Chihaia, S. Nicolaie, A. Nedelcu, and M. Popescu, "Wind tunnel testing for a new experimental model of counter-rotating wind turbine," Procedia Eng., vol. 100, no. January, pp. 1141-1149, 2015.

L. Zhiqiang, W. Yunke, H. Jie, Z. Zhihong, and C. Wenqi, "The study on performance and aerodynamics of micro counter-rotating HAWT,” Energy, vol. 161, pp. 939-954, 2018.

M. Bakırc1 and S. Y1lmaz, "Theoretical and computational investigations of the optimal tipspeed ratio of horizontal-axis wind turbines," Eng. Sci. Technol. an Int. J., vol. 21, no. 6, pp. 1128-1142, 2018.

R. J. Conzemius, "WIND TURBINE AND SODAR OBSERVATIONS OF WAKES IN A LARGE WIND FARM," 19th Symp. Bound. Layers Turbul., 2010.

R. K. Singh and M. R. Ahmed, "Blade design and performance testing of a small wind.

S. Lee, H. Kim, and S. Lee, "Analysis of aerodynamic characteristics on a counter-rotating wind turbine,” Curr. Appl. Phys., vol. 10, no. 2 SUPPL., pp. S339-S342, 2010.

S. Lee, H. Kim, E. Son, and S. Lee, "Effects of design parameters on aerodynamic performance of a counter-rotating wind turbine," Renew. Energy, vol. 42, pp. 140-144, 2012.

S. Martosaputro and N. Murti, "Blowing the wind energy in Indonesia," Energy Procedia, vol. 47, pp. 273-282, 2014.

S. S. Navin Prasad E, Janakiram S, Prabu T, "Design and development of horizontal small wind turbine blade for low wind speeds,” Int. J. Eng. Sci. Adv. Technol., no. 1, pp. 75-84, 2014.

S. W. Buana, V. A. Koehuan, A. Riszal, S. Kamal, and S. Sugiyono, “Analisi Pengaruh Rasio Diameter sebagai Parameter Kinerja Aerodinamika Dual Rotor Counter-rotating Wind Turbine," Pros. Semnastek, no. November, pp. 1-10, 2016.

Y. Wei, T. Wei, O. Ahmet, and H. U. Hui, "An experimental study on the effects of relative rotation direction on the wake interferences among tandem wind turbines," Sci. China Physics, Mech. Astron., vol. 57, no. 5, pp. 935-949, 2014.

Z. Wang, W. Tian, A. Ozbay, A. Sharma, and H. Hu, "An experimental study on the aeromechanics and wake characteristics of a novel twin-rotor wind turbine in a turbulent boundary layer flow," Exp. Fluids, vol. 57, no. 9, pp. 1-17, 2016. 